\title{
IDENTIFIKASI KENDALA DAN MASALAH DALAM PROSES PEMBELAJARAN MATEMATIKA
}

\author{
Zulkahfi Dalimunthe \\ SMPN 1 Bandar Baru \\ e-mail: zulfahmidalimunthbb@gmail.com
}

\begin{abstract}
ABSTRAK
Tujuan penelitian ini adalah untuk mengidentifikasi kendala dan masalah yang dihadapi oleh guru dalam pembelajaran matematika tingkat SMP. Subjek dalam penelitian ini adalah guru matematika dari sepuluh sekolah tingkat SMP di kabupaten Pidie Jaya yang berjumlah 15 orang dengan pemilihan secara purposive sampling. Jenis penelitian adalah kualitatif deskriptif. Data penelitian didapat dari hasil kegiatan MGMP (Musyawarah Guru mata Pelajaran) dengan dua kategori yaitu materi yang sulit diajarkan, dan proses pembelajaran yang sulit untuk materi tertentu. Hasil penelitian didapat bahwa beberapa materi yang sulit diajarkan adalah Barisan dan Deret, Kesebangunan, Statistik, Aljabar (pangkat dalam akar), Geometri, Peluang, dan Persamaan dan Pertidaksamaan Linear. Untuk proses pembelajaran yang dirasakan sulit untuk materi tertentu yaitu Aljabar (KPK, FPB dan SPLDV), Deret/pola Bilangan, Kesebangunan, Pangkat tak Sebenarnya, Perbandingan, Bangun Datar, dan Statistik.
\end{abstract}

Kata kunci: kendala, masalah, pembelajaran matematika, materi sulit

\begin{abstract}
The purpose of this study is to identify the constraints and problems faced by teachers in junior high school mathematics learning. The subjects in this study were mathematics teachers from ten junior high school level in Pidie Jaya district, amounting to 15 people with purposive sampling. This type of research is descriptive qualitative. The research data was obtained from the results of MGMP activities (Subject Teacher Consultation) with two categories, namely material that was difficult to teach, and a difficult learning process for certain material. The results of the study show that some material that is difficult to teach is the sequence and series, congruence, statistics, algebra (rank in roots), geometry, opportunities, and equations and linear inequalities. For the learning process that is felt difficult for certain materials, namely Algebra (KPK, FPB and SPLDV), Series / pattern numbers, congruence, not actual rank, comparison, flat build, and statistics.
\end{abstract}

Keywords: constraints, problems, learning mathematics, difficult material

\section{PENDAHULUAN}

Matematika adalah salah satu mata pelajaran yang dipelajari pada setiap jenjang pendidikan, mulai dari pendidikan dasar. Hal ini menyebabkan setiap orang yang menempuh jenjang pendidikan mengenal dan mengetahui materi matematika. Akan tetapi, hal ini tidak serta merta membuat setiap orang memahami materi matematika secara tepat dan mendalam. Apalagi materi matematika diajarkan secara terstruktur di mulai dari dasar sampai dengan materi komplit. Selain itu, materi yang diajarkan pada setiap jenjang pendidikan pun berbedabeda tingkatannya.

Hadi (2005) menyatakan bahwa matematika sangat berperan dalam kehidupan karena dengan matematika dapat meningkatkan pengetahuan berfikir secara logis, rasional, kritis, cermat, efektif dan efisien. Setiap orang akan menyenangi matematika apabila sudah menyukainya sejak awal. Hal 
ini selain didukung dari pribadi orang yang menyukai matematika, juga didukung oleh pengalaman proses pembelajaran yang didapat selama mempelajari matematika. Pengalaman ini sangat menentukan seseorang senang terhadap matematika. Dalam hal ini, proses pembelajaran sangat terkait dengan cara atau model pembelajaran yang diterapkan guru supaya pembelajarannya menyenangkan.

Penerapan model pembelajaran ataupun cara yang tepat dalam pembelajaran matematika sangat ditentukan juga dari kemampuan guru dalam menguasai pembelajaran. Hal ini dikarenakan pengua-saan materi matematika dengan tepat akan sangat memudahkan guru dalam menyam-paikan materi tersebut kepada siswa. Seperti yang dinyatakan oleh Hasan (2015) bahwa kemampuan guru sangat dibutuhkan dalam pengelolaan proses pembelajaran matematika sehingga keterlibatan siswa berdampak optimal dan juga pada hasil belajar siswa. Beberapa hal yang dapat dilakukan antara lain melakukan atau menerapkan variasi metode dan atau model pembelajaran serta menyesuaikan dengan pokok bahasan yang diajarkan.

Berdasarkan hasil observasi di beberapa sekolah tingkat SMP di Kabupaten Pidie Jaya, didapat bahwa sebagian besar guru mengalami kendala dalam mengajarkan beberapa materi matematika. Hal ini dikarenakan ada materi yang sulit dijelaskan ke siswa karena beragamnya permasalahan seperti materi

Statistika, Peluang, Barisan dan Deret. Selain itu, ada materi yang sulit dipahami oleh guru sendiri. Permasalahan ini harus menjadi perhatian untuk meminimalisir dampak yang ditimbulkan seperti menurunnya kemampuan siswa dalam penguasaan materi dan juga hasil belajar siswa.

Utomo (2011) mengelompokkan masalah dalam pembelajaran matematika di SMP menurut komponen pembelajaran, yaitu materi, metode, media, evaluasi, dan penge- lolaan kelas. Selanjutnya masalah tersebut dikaitkan dengan teori-teori psikologi.

Tujuan penelitian ini adalah untuk mengidentifikasi kendala dan masalah yang dihadapi guru matematika dalam proses pembelajaran matematika di SMP Kabupaten Pidie Jaya, Aceh. Dalam hal ini kendala dilihat dari dua aspek yaitu materi yang sulit diajarkan, dan proses pembelajaran yang sulit untuk materi tertentu.

\section{METODE PENELITIAN}

Jenis penelitian yang digunakan adalah penelitian deskriptif dengan pendekatan kualitatif. Hal ini dikarenakan data yang didapat dari hasil diskusi dalam Forum Guru Mata Pelajaran (MGMP) akan dideskripsikan dengan menyesuaikan tujuan penelitian. Subjek yang dilibatkan adalah 15 orang guru matematika dari sepuluh sekolah tingkat SMP Kabupaten Pidie Jaya yang dipilih secara purposive sampling. Dalam kegiatan MGMP, identifikasi permasalahan dibagi dalam dua kategori yaitu materi yang sulit diajarkan, dan pembelajaran yang dirasakan sulit untuk materi tertentu.

\section{HASIL DAN PEMBAHASAN}

Kegiatan MGMP dilaksanakan selama 1 hari dalam satu minggu dengan durasi waktu dua jam pelajaran setiap tatap muka, kegiatan MGMP dilaksanakan di SMPN 1 Bandar Baru. Kegiatan ini didampingi oleh tiga orang guru senior yang lulus nilai $\mathrm{KKG}$ tahun 2017 Pada sesi pertama pelaksanaan MGMP, narasumber memaparkan tujuan, permasa-lahan, dan proses kegiatan selama MGMP. Interaksi antara peserta dan narasumber terjadi selama pelaksanaan MGMP. Peserta juga diminta mendiskusikan permasalahan yang diberikan dalam kelompok yang sudah ditentukan. Selanjutnya mempresentasikan hasil diskusi kelompok. Pada sesi akhir narasumber memberikan penguatan dan beberapa solusi terkait permasalahan yang ditanyakan atau yang didiskusikan.

Terdapat beberapa materi yang dianggap sulit untuk diajarkan kepada siswa. 
Rangkuman hasil diskusi tersebut dapat dilihat pada Tabel 1.

Berdasarkan Tabel 1 dapat dilihat bahwa terdapat sejumlah materi yang dirasakan sulit bagi guru. Untuk materi Deret Bilangan, sebagian besar guru merasakan sulit. Hal ini dikarenakan soal-soal tentang deret sangat beragam dan penyelesaiannya juga sangat berbeda-beda. Padahal, apabila guru memahami konsep deret ini sangat mudah untuk menyelesaikan dan menjelaskan ke siswa. Tidak hanya deret tetapi juga barisan yang terkait dengan aritmatika dan geometri. Apabila dalam suatu permasalahan atau soal tidak dicantukamkan apakah barisan/deret aritmatika atau geometri, sebagian guru akan kebingungan menentukan dan membedakannya.

Terkait kesebangunan, kesulitan yang dihadapi dan dialami guru adalah tentang perbandingan. Dalam hal ini guru masih sangat kurang pemahamannya tentang konsep perbandingan. Apalagi jika perbandingan yang diberikan dikaitkan dengan materi yang lain seperti luas bangun datar atau sejumlah segitiga yang dikaitkan.

Hampir semua guru sulit memahami salah satu soal Statistika yang diberikan yaitu terkait rata-rata gabungan. Dalam hal ini soal yang diberikan tidak langsung ditanyakan tentang rata-rata gabungan dari beberapa aspek tetapi aspek yang ditanyakan dengan rata-rata gabungan yang diketahui.

Hal ini menyebabkan sebagian guru sulit menerjemahkan permasalahan yang diberikan. Selain itu, guru juga lupa penggunaan rumus yang tepat.

Tabel 1. Materi yang Dianggap Sulit untuk Diajarkan

\begin{tabular}{|l|l|l|}
\hline No & Materi & Sub Materi \\
\hline 1. & $\begin{array}{l}\text { Deret } \\
\text { Bilangan }\end{array}$ & $\begin{array}{l}\text { a. Deret Aritmatika } \\
\text { a. Deret Geometri }\end{array}$ \\
\hline 2. & $\begin{array}{l}\text { Kesebangu } \\
\text { nan }\end{array}$ & $\begin{array}{l}\text { Rasio Sisi-Sisi Segi } \\
\text { a. Tiga Siku-Siku } \\
\text { b } \\
\text {. Segitiga Kongruen }\end{array}$
\end{tabular}

\begin{tabular}{|l|l|l|} 
& & $\begin{array}{l}\text { c. Diagram Lingkaran } \\
\text { d } \\
\text { Trapesium } \\
\text { Bangun yang } \\
\text { e. Sebangun } \\
\text { Konsep } \\
\text { Kesebangunan Dua } \\
\text { f. Bangun }\end{array}$ \\
\hline 3. & Statistika & Rata-Rata Gabungan \\
\hline 5. & $\begin{array}{l}\text { Pangkat } \\
\text { dalam Akar }\end{array}$ & $\begin{array}{l}\text { Operasi Pangkat Tak } \\
\text { Sebenarnya }\end{array}$ \\
\hline Geometri & $\begin{array}{l}\text { a. Garis-Garis Segitiga } \\
\text { b Garis Singgung } \\
\text { Lingkaran } \\
\text { Lingkaran, Segi } \\
\text { a. Empat Tali Busur }\end{array}$ \\
\hline 7. & $\begin{array}{l}\text { Dalil } \\
\text { Phytagoras }\end{array}$ & $\begin{array}{l}\text { Pembuktian Dalil } \\
\text { Phytagoras }\end{array}$ \\
\hline 8. & $\begin{array}{l}\text { Beluang } \\
\text { Bulat }\end{array}$ & $\begin{array}{l}\text { Kejadian Saling Lepas } \\
\text { dan Saling Ikat }\end{array}$ \\
\hline & $\begin{array}{l}\text { Persamaan/ } \\
\text { Pertidaksa } \\
\text { maan }\end{array}$ & \\
\hline
\end{tabular}

Dalam memahami materi tentang Aljabar yang berkaitan dengan nilai berpangkat dalam akar, beberapa guru kesulitan dalam menjelaskan tentang operasi pangkat yang tak sebenarnya. Penyelesaian soal seperti ini membutuhkan pemahaman yang kuat tentang aljabar dan operasinya, apalagi terkait dengan nilai berpangkat atau dalam bentuk akar.

Materi Geometri juga dirasakan sulit bagi guru terutama yang berkaitan dengan garis singgung lingkaran dan juga segiempat tali busur. Dalam hal ini tidak hanya dibutuhkan pemahaman tentang lingkaran tetapi juga kaitannya dengan materi lain seperti garis singgung.

Materi berkenaan dengan dalil phytagoras sering kali dibahas dalam kaitannya dengan segitiga siku-siku. Akan tetapi kesulitan yang dialami guru adalah dalam mengajarkan pembuktiannya kepada siswa. Padahal materi ini termasuk materi yang 
tidak begitu sukar apabila guru memahami konsepnya. Secara konstektual pun dapat dijelaskan kepada siswa seperti menghitung panjang diagonal sisi lantai yang berubin.

Materi peluang sering kali dianggap sulit karena beragamnya model permasalahan yang ditawarkan. Dalam penyelesaiannya dituntut harus memiliki kemampuan analisis dan pemahaman terhadap permasalahan dalam setiap soal atau masalah yang diberikan. Menurut (Godino, Juan D; Batanero, Carmen; Roa, 2001) sulitnya me-ngajarkan materi Peluang karena kurangnya dukungan dari buku teks dan dokumen kurikulum yang disiapkan untuk guru.

Terkait materi Bilangan Bulat yang berkenaan dengan pola bilangan dianggap sulit karena terkait juga dengan materi Barisan dan Deret.

Untuk proses pembelajaran yang dirasakan sulit untuk materi tertentu sangat berkaitan juga dengan materi matematika yang sulit bagi guru untuk diajarkan ke siswa. Dalam hal ini materi yang sulit di-ajarkan berdampak pada pelaksanaan pembelajaran yang tidak tepat. Untuk hasil diskusi terkait pembelajaran yang sulit untuk materi tertentu dapat dilihat pada Tabel 2.

Berdasarkan Tabel 2 dapat dilihat bahwa proses pembelajaran yang sulit untuk materi tertentu juga didasarkan pada materi yang sulit dipahami oleh guru. Ada beberapa materi yang sulit untuk dijelaskan dengan penerapan model-model pembelajaran. Hal ini dikarenakan sebagian guru kurang memahami pada beberapa materi matematika sehingga berdampak pada sulitnya mengajarkan materi tersebut kepada siswa.

Hasil penelitian Hasibuan (2015) menunjukkan bahwa penyebab kesulitan belajar siswa dikarenakan 1) pemahaman konsep dasar aljabar yang rendah; 2) kurangnya minat/kemauan; 3) kurangnya latihan untuk mengerjakan soal-soal bentuk aljabar; 4) kesulitan menganalisis soal cerita; 6) pembelajaran aljabar yang kurang bermakna.
Tabel 2. Proses Pembelajaran yang Dirasakan Sulit untuk Materi Tertentu

\begin{tabular}{|c|c|c|c|}
\hline No. & Materi & Sub Materi & $\begin{array}{l}\text { Kendala yang } \\
\text { Dihadapi }\end{array}$ \\
\hline 1. & $\begin{array}{l}\text { Bilangan } \\
\text { Bulat }\end{array}$ & $\begin{array}{l}\text { Menentukan } \\
\text { KPK } \\
\\
\text { dan FPB } \\
\text { dengan } \\
\text { Faktorisasi }\end{array}$ & $\begin{array}{l}\text { a. Tidak mengetahui } \\
\text { alat peraga yang } \\
\text { tepat } \\
\text { b. Tidak mengerti } \\
\text { cara penyampaian } \\
\text { yang menarik agar } \\
\text { siswa mudah } \\
\text { mengerti }\end{array}$ \\
\hline 2. & $\begin{array}{l}\text { Deret/Pola } \\
\text { Bilangan }\end{array}$ & \begin{tabular}{|l} 
a. Deret \\
Aritmatika \\
b. Deret \\
Geometri \\
c. Pola dan \\
Barisan \\
$\quad$ Bilangan \\
\end{tabular} & $\begin{array}{ll}\text { a. } & \text { Pada suku ke-n, } \\
& \mathrm{Sn}=\ldots \\
\text { b. } & \text { Tidak tahu cara } \\
& \text { menentukan } \\
& \text { rumus }\end{array}$ \\
\hline 3. & $\begin{array}{l}\text { Kesebang } \\
\text { unan }\end{array}$ & 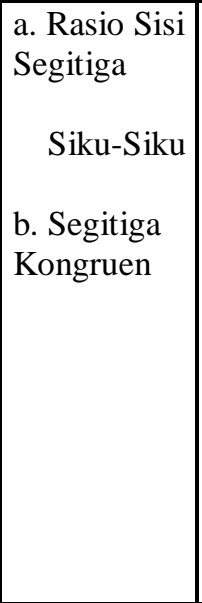 & \begin{tabular}{|l} 
a. Proyeksi sisi alas \\
pada sisi miring \\
b. Proyeksi sisi tegak \\
pada sisi miring \\
c. Siswa sering lupa \\
membedakan \\
garis \\
bagi, tinggi, berat, \\
dan sumbu \\
d. Sulit \\
mempraktikkan \\
rumus luas karena \\
siswa sampai 48 \\
orang dalam satu \\
kelas
\end{tabular} \\
\hline 4. & \begin{tabular}{|l|} 
Pangkat \\
Tak \\
Sebenarny \\
a
\end{tabular} & $\begin{array}{l}\text { Operasi } \\
\text { pangkat tak } \\
\text { Sebenarnya }\end{array}$ & $\begin{array}{l}\text { Cara penyampaian } \\
\text { dan penyelesaian } \\
\text { yang } \\
\text { mudah di pahami }\end{array}$ \\
\hline 5. & $\begin{array}{l}\text { Perbandin } \\
\text { gan }\end{array}$ & Skala & $\begin{array}{l}\text { Tidak mengerti cara } \\
\text { penyampaian yang } \\
\text { menarik karena } \\
\text { siswa lebih } 40 \text { orang }\end{array}$ \\
\hline 6. & $\begin{array}{l}\text { Bangun } \\
\text { Datar }\end{array}$ & \begin{tabular}{|l} 
Konsep \\
Dasar \\
Bangun \\
Datar \\
\end{tabular} & $\begin{array}{l}\text { Tidak mengerti } \\
\text { model pembelajaran } \\
\text { yang } \\
\text { menarik agar siswa } \\
\text { mudah memahami } \\
\end{array}$ \\
\hline 7. & Statistika & $\begin{array}{l}\text { Rata-Rata } \\
\text { Gabungan }\end{array}$ & $\begin{array}{l}\text { Tidak bisa } \\
\text { menyelesaikan soal } \\
\text { seperti no. } \\
9 \text { tes kompetensi } \\
\text { profesional yang } \\
\text { diberikan }\end{array}$ \\
\hline
\end{tabular}


\begin{tabular}{|l|l|l|l|}
8. & Aljabar & SPLDV & $\begin{array}{l}\text { a. Siswa sering lupa } \\
\text { dengan suku sejenis } \\
\text { b. } \\
\text { Penjumlahan/pengur } \\
\text { angan pada } \\
\text { koefisien yang negatif }\end{array}$ \\
\hline
\end{tabular}

\section{KESIMPULAN}

Berdasarkan hasil penelitian dapat disimpulkan bahwa kendala sebagian besar guru matematika yaitu apabila permasalahan yang diberikan berkaitan dengan materi perbandingan. Beberapa materi yang sulit diajarkan adalah Barisan dan Deret, Kesebangunan, Statistik, Aljabar (pangkat dalam akar), Geometri, Peluang, dan Persamaan dan Pertidaksamaan Linear. Untuk proses pembelajaran yang dirasakan sulit untuk materi tertentu yaitu Aljabar (KPK, FPB dan SPLDV), Deret/pola Bilangan, Kesebangunan, Pangkat tak Sebenarnya, Perbandingan, Bangun Datar, dan Statistik.

\section{UCAPAN TERIMAKASIH}

Artikel ini merupakan bagian dari hasil penelitian tahun 2017, Penulis mengucapkan terimakasih kepada Pengurus MGMP Matematika Pidie Jaya, Kepala Sekolah dan Dewan Guru SMPN 1 Bandar Baru atas kesempatan dan kepercayaan yang diberikan, semoga hasil penelitian ini dapat bermanfaat bagi kemajuan pendidikan di Indonesia.

\section{DAFTAR PUSTAKA}

Godino, Juan D; Batanero, Carmen; Roa, R. (2001). Training teachers to teach statistics. IASE/ISI Satellite.

Hasan, H. (2015). Kendala yang Dihadapi Guru dalam Proses Belajar Mengajar Matematika di SD Negeri Gani Kabupaten Aceh Besar. Jurnal Pesona Dasar, 1(4), 40-51.
Hasibuan, I. (2015). Hasil Belajar Siswa pada Materi Bentuk Aljabar di Kelas VII SMP Negeri 1 Banda Aceh Tahun Pelajaran 2013/2014. Jurnal Peluang, 4(1), 5-11. 